\title{
Pacific
}

Journal of

Mathematics

\section{CORRECTION TO THE ARTICLE \\ A FLOER HOMOLOGY FOR EXACT CONTACT EMBEDDINGS}

Kai Cieliebak ANd URS AdRian FraUenfelder 


\title{
CORRECTION TO THE ARTICLE A FLOER HOMOLOGY FOR EXACT CONTACT EMBEDDINGS
}

\author{
Kai Cieliebak And Urs Adrian Frauenfelder
}

Volume 239:2 (2009), 251-316

\begin{abstract}
The paper in question included an appendix, titled "A Wasserman-type theorem for the Rabinowitz action functional", where we showed that the Rabinowitz action functional is generically Morse-Bott and the Morse-Bott manifold is the disjoint union of the energy hypersurface itself, representing the constant Reeb orbits, and a circle for each Reeb orbit. The treatment of multiple covered Reeb orbits contained a gap, which is filled in this note.
\end{abstract}

Appendix B of s devoted to showing that the Rabinowitz action functional is generically Morse-Bott and the corresponding Morse-Bott manifold is the disjoint union of the energy hypersurface itself, representing the constant Reeb orbits, and a circle for each Reeb orbit. Here we fix a gap in the proof, pointed out to us by Will Merry and Gabriel Paternain.

In the Claim in Step 2 of the proof of Theorem B.1 we asserted that $\bar{D} S(H, w)$ is surjective for every $(H, w) \in S^{-1}(0)$ whenever $w$ is not a fixed point of the $S^{1}$ action. This assertion is incorrect as stated; it is only true if the underlying Reeb orbit $v$ is simple. The trouble is inequality (70), which a priori only holds in a neighborhood of $t_{0}$, and might fail to hold globally on the circle if the Reeb orbit is multiply covered and hence comes back to $v\left(t_{0}\right)$. Therefore the proof of Theorem B.1 as it stands only proves that the Rabinowitz action functional is generically Morse-Bott on the constant and simple Reeb orbits.

To prove the full assertion of Theorem B.1 we need to show in addition that generically no root of unity arises as an eigenvalue of the linearized Reeb flow at a simple periodic orbit. But this fact follows from a classical theorem of C. Robinson [1970, Lemma 19].

Here is how this works. For $T>0$ and $k \in \mathbb{N}$, denote by $U(T, k) \subset C_{c}^{\infty}(V)$ the subset of Hamiltonians $H$ with the following properties. If $k=1$, then $U(T, 1)$ consists of all Hamiltonians such that the Rabinowitz action functional $\mathscr{A}^{H}$ is Morse-Bott at the constant Reeb orbits and all simple Reeb orbits of period less

MSC2000: 53D10, 53D40.

Keywords: contact manifolds, Floer homology, Rabinowitz action functional. 
than or equal to $T$ (since the Reeb orbit is allowed to traverse backwards we here actually mean the absolute value of the period). If $k \geq 2$ then $U(T, k) \subset U(T, 1)$ consists of all $H \in \mathcal{U}(T, 1)$ with the additional property that the linearized Reeb flow at each simple Reeb orbit of period less than or equal to $T$ has no eigenvalues equal to roots of unity of order less than or equal to $k$. As it follows from our arguments in the proof of Theorem B.1, for each $T>0$ the subset $U(T, 1)$ is open and dense in $C_{c}^{\infty}(V)$. If $H \in \mathcal{U}(T, 1)$, we deduce from the Arzelà-Ascoli Theorem that there are only finitely many simple Reeb orbits of period at most $T$. Hence by Robinson's result for each $k \in \mathbb{N}$ the subset $U(T, k)$ is dense in $U(T, 1)$. Again by Arzelà-Ascoli $U(T, k)$ is also open in $U(T, 1)$. Hence we conclude that for each $T>0$ and for each $k \in \mathbb{N}$ the set $U(T, k)$ is open and dense in $C_{c}^{\infty}(V)$. Now set

$$
u=\bigcap_{\substack{N \in \mathbb{N} \\ k \in \mathbb{N}}} U(N, k) .
$$

The subset $\mathcal{U}$ is obviously of second category in $C_{c}^{\infty}(V)$ and if $H \in \mathcal{U}$ then the Rabinowitz action functional $\mathscr{A}^{H}$ is Morse-Bott at the constants and at all simple Reeb orbits. Moreover, the linearized Reeb flow at each simple Reeb orbit has no root of unity as eigenvalue. Hence $\mathscr{A}^{H}$ is Morse-Bott at all Reeb orbits and its critical manifold consists of the disjoint union of a copy of the hypersurface and circles for each nontrivial Reeb orbit. This fills up the gap in Appendix B.

\section{References}

[Robinson 1970] R. C. Robinson, "Generic properties of conservative systems", Amer. J. Math. 92 (1970), 562-603. MR 42 \#8517

Received September 28, 2010.

Kai Cieliebak

DEPARTMENT OF MATHEMATICS

LUDWIG-MAXIMILIAN UNIVERSITY

THERESIENSTRASSE 39

D-80333 MUNICH

GERMANY

kai@mathematik.uni-muenchen.de

URS ADRIAN FRAUENFELDER

DEPARTMENT OF MATHEMATICS AND RESEARCH Institute of Mathematics

SEOUL NATIONAL UNIVERSITY

SEOUL 151-747

SOUTH KOREA

frauenf@snu.ac.kr 


\title{
PACIFIC JOURNAL OF MATHEMATICS
}

\author{
http://www.pjmath.org \\ Founded in 1951 by
}

E. F. Beckenbach (1906-1982) and F. Wolf (1904-1989)

\section{EDITORS}

V. S. Varadarajan (Managing Editor)

Department of Mathematics

University of California

Los Angeles, CA 90095-1555

pacific@math.ucla.edu

Vyjayanthi Chari

Department of Mathematics

University of California

Riverside, CA 92521-0135

chari@math.ucr.edu

\section{Robert Finn}

Department of Mathematics Stanford University

Stanford, CA 94305-2125

finn@math.stanford.edu

Kefeng Liu

Department of Mathematics

University of California

Los Angeles, CA 90095-1555

liu@math.ucla.edu
Darren Long

Department of Mathematics

University of California

Santa Barbara, CA 93106-3080

long@math.ucsb.edu

Jiang-Hua Lu

Department of Mathematics

The University of Hong Kong

Pokfulam Rd., Hong Kong jhlu@maths.hku.hk

Alexander Merkurjev

Department of Mathematics University of California

Los Angeles, CA 90095-1555 merkurev@math.ucla.edu
Sorin Popa

Department of Mathematics

University of California

Los Angeles, CA 90095-1555

popa@math.ucla.edu

Jie Qing

Department of Mathematics

University of California

Santa Cruz, CA 95064

qing@ cats.ucsc.edu

Jonathan Rogawski

Department of Mathematics

University of California

Los Angeles, CA 90095-1555

jonr@math.ucla.edu

\section{PRODUCTION}

pacific@math.berkeley.edu

Silvio Levy, Scientific Editor Matthew Cargo, Senior Production Editor

ACADEMIA SINICA, TAIPEI

CALIFORNIA INST. OF TECHNOLOGY

INST. DE MATEMÁTICA PURA E APLICADA

KEIO UNIVERSITY

MATH. SCIENCES RESEARCH INSTITUTE

NEW MEXICO STATE UNIV.

OREGON STATE UNIV.

\section{SUPPORTING INSTITUTIONS}

STANFORD UNIVERSITY
UNIV. OF BRITISH COLUMBIA
UNIV. OF CALIFORNIA, BERKELEY
UNIV. OF CALIFORNIA, DAVIS
UNIV. OF CALIFORNIA, LOS ANGELES
UNIV. OF CALIFORNIA, RIVERSIDE
UNIV. OF CALIFORNIA, SAN DIEGO
UNIV. OF CALIF., SANTA BARBARA

UNIV. OF CALIF., SANTA CRUZ

UNIV. OF MONTANA

UNIV. OF OREGON

UNIV. OF SOUTHERN CALIFORNIA

UNIV. OF UTAH

UNIV. OF WASHINGTON

WASHINGTON STATE UNIVERSITY

These supporting institutions contribute to the cost of publication of this Journal, but they are not owners or publishers and have no responsibility for its contents or policies.

See inside back cover or www.pjmath.org for submission instructions.

The subscription price for 2011 is US \$420/year for the electronic version, and \$485/year for print and electronic.

Subscriptions, requests for back issues from the last three years and changes of subscribers address should be sent to Pacific Journal of Mathematics, P.O. Box 4163, Berkeley, CA 94704-0163, U.S.A. Prior back issues are obtainable from Periodicals Service Company, 11 Main Street, Germantown, NY 12526-5635. The Pacific Journal of Mathematics is indexed by Mathematical Reviews, Zentralblatt MATH, PASCAL CNRS Index, Referativnyi Zhurnal, Current Mathematical Publications and the Science Citation Index.

The Pacific Journal of Mathematics (ISSN 0030-8730) at the University of California, c/o Department of Mathematics, 969 Evans Hall, Berkeley, CA 94720-3840, is published monthly except July and August. Periodical rate postage paid at Berkeley, CA 94704, and additional mailing offices. POSTMASTER: send address changes to Pacific Journal of Mathematics, P.O. Box 4163, Berkeley, CA 94704-0163.

PJM peer review and production are managed by EditFLOW ${ }^{\mathrm{TM}}$ from Mathematical Sciences Publishers.

PUBLISHED BY PACIFIC JOURNAL OF MATHEMATICS

at the University of California, Berkeley 94720-3840

A NON-PROFIT CORPORATION

Typeset in IATEX

Copyright $(2011$ by Pacific Journal of Mathematics 


\section{PACIFIC JOURNAL OF MATHEMATICS}

Volume $249 \quad$ No. $2 \quad$ February 2011

A gluing construction for prescribed mean curvature

257

ADRIAN BUTSCHER

Large eigenvalues and concentration

271

BRUNO COLBOIS and ALESSANDRO SAVO

Sur les conditions d'existence des faisceaux semi-stables sur les courbes multiples primitives

JEAN-MARC DRÉZET

A quantitative estimate for quasiintegral points in orbits

LIANG-CHUNG HSIA and JosePh H. Silverman

Möbius isoparametric hypersurfaces with three distinct principal curvatures, II

ZEJUN HU and SHUJIE ZHAI

Discrete Morse theory and Hopf bundles

371

DMITRY N. KOZLOV

Regularity of canonical and deficiency modules for monomial ideals

ManOJ KUMmini and SATOSHI MURAI

$\mathrm{SL}_{2}(\mathbb{C})$-character variety of a hyperbolic link and regulator

WEIPING LI and QINGXUE WANG

Hypergeometric evaluation identities and supercongruences

LING LONG

Necessary and sufficient conditions for unit graphs to be Hamiltonian

H. R. Maimani, M. R. Pournaki and S. Yassemi

Instability of the geodesic flow for the energy functional

DOMENico PERrone

String structures and canonical 3-forms

CORBETT REDDEN

Dual pairs and contragredients of irreducible representations

BINYONG SUN

On the number of pairs of positive integers $x_{1}, x_{2} \leq H$ such that $x_{1} x_{2}$ is a $k$-th power

DOYCHIN I. TOLEV

Correction to the article A Floer homology for exact contact embeddings 